\title{
OPTIMAL DESIGN OF HIGH-RISE BUILDING BUNDLED TUBE SYSTEMS
}

\author{
Hojat Allah Ghasemi ${ }^{1}$
}

1 Department of Civil Engineering, Tehran University Imam Hussein, Iran, e-mail: hojatallahghasemi@ gmail.com

Received: 2016.04 .15

Accepted: 2016.05 .10

Published: 2016.06.01

\begin{abstract}
The primary objectives of this study are to investigate the effects of varying design parameters on the tube action and shear lag behavior of a typical reinforced concrete bundled tube building, and propose optimal design approaches for similar structures. A parametric study was conducted with selected key design variables on the performance of a 41 story building. The design variables considered for the parametric study include the column depth, beam depth, column width and beam width of the moment frames. The performance of each model was assessed in terms of overall and critical (maximum) story drifts, and shear lag behavior. Overall, the effects of the column depth on the tube action and shear lag behavior were more prominent than the other member dimensions.
\end{abstract}

Keywords: bundled tube, optimal design, high-rise building, shear lag.

\section{INTRODUCTION}

A building framed-tube system is considered one of the most efficient lateral force-resisting systems. Modern high-rise buildings of the framed-tube system exhibit a considerable degree of shear-lag with consequential reduction in structural efficiency. These buildings are usually equipped with service cores or internal tubes that are often designed to provide added lateral stiffness to the building. The internal tubes also interact with each other as well as with the external tube. The true behavior of the tube structure is influenced by shear-lag arising from the tube action which results in a nonlinear stress distribution. It is no wonder that a significant amount of research work has been done on the shear-lag phenomenon in framed tubes. The bundled tube system can be visualised as an assemblage of individual tubes resulting in multiple cell tube. The increase in stiffness is individual tubes resulting in multiple cell tube. The increase in stiffness is apparent. The system allows for the greatest height and the most floor area. This structural form was used in the Sears Tower in Chicago. In this system, introduction of the internal webs greatly reduces the shear lag in the flanges. Hence, their columns are more evenly stressed than in the single tube structure and their contribution to the lateral stiffness is greater. Kristek and Bauer (1993), Singh and Nagpal (1995) and Lee et al. (2002) extended the study to examine the shear lag behavior of framed-tube buildings. In a framed-tube system, columns play a role in making up discontinuous segments of the building tube section that are potentially available for the tube action, and the role of spandrel beams is to effectively engage the discontinuous section segments together, so that they can be fully utilized for the tube action. Therefore, the tube action can be improved by adjusting column and spandrel beam sizes, and/or perimeter column spacing. Lee et al. (2002) conducted a parametric study by changing the axial and bending stiffness properties of columns and beams, and reported that the axial stiffness of the columns was the most influential factor on the tube action as well as the shear lag behavior, while the bending stiffness of the columns and beams were of little impact perhaps due to the tube-totube interaction. However, the variables used in this parametric study appear to be unreasonable from a practical standpoint, because changing 


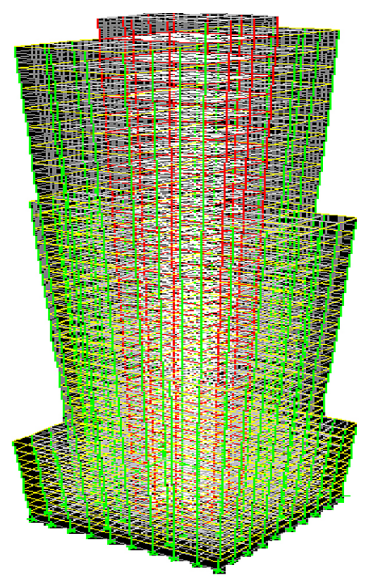

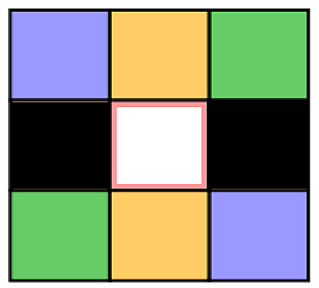

1-10 Floors

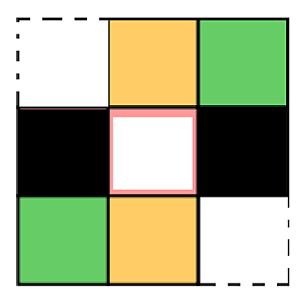

11-20 Floors

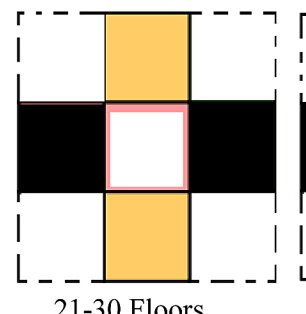

21-30 Floors

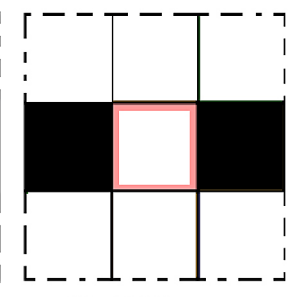

31-40 Floors

Fig. 1. 3-D model of 41-storey concrete building (a) and place of column cutting (b)

one stiffness property of a member typically accompanies changes in other stiffness properties of the member (and even other members in some cases) in real design, which was not taken into account in Lee et al. (2002). For example, varying the column sectional dimension parallel to the frame direction affects not only the stiffness of the column, but also the stiffness of the beams framing into the column (by reducing the clear span length of the beams).

\section{STRUCTURAL SYSTEM OF THE CASE STUDY BUILDING}

Figure 1 illustrates a 3-D model of 41-storey concrete building (a) and place of column cutting (b). The structure is $148 \mathrm{~m}$ tall, and is $32.4 \times 32.4 \mathrm{~m}$ (wide $\times$ length).The story height is $4 \mathrm{~m}$ at the first story and $3.6 \mathrm{~m}$ at the upper story. Slab and shear wall thickness are 250 and $500 \mathrm{~mm}$ for all typical floors. The concrete compressive strengths $400\left(\mathrm{~kg} / \mathrm{cm}^{2}\right)$ were used for all members.

\section{DESIGN VARIABLES FOR PARAMETRIC STUDY}

The primary goal of this study is to propose design approaches towards the optimal design of bundled tube structures that are similar to the case study building. The performance of any model was assessed in terms of overall building and critical (maximum) story drifts, as well as force distributions among various lateral force-resisting members (e.g., between the flange and web members of the tube structure, and among the flange columns). Also, the degree of shear lag for each model was evaluated as one of the important performance indicators.

Design variables used for this study include sectional dimensions of the exterior moment frame members: the depth of columns (hc), depth of beam (hb), width of columns (bc) and width of beams (bb). In each model, an identical set of sectional dimensions is given to all columns and beams at all typical floors for simplicity and in any model section of corner column is considered $1 \times 1 \mathrm{~m}$. Table 1 summarizes model design variables and their relative ratios for all investigated models.

Table 1. Model design variables and descriptions

\begin{tabular}{|c|c|c|c|c|}
\hline Model & $\mathrm{bc}$ & $\mathrm{hc}$ & $\mathrm{bb}$ & $\mathrm{hb}$ \\
\hline $\mathrm{mOO}$ & 0.6 & 0.6 & 0.6 & 0.6 \\
\hline $\mathrm{mlO}$ & 0.6 & 0.8 & 0.6 & 0.6 \\
\hline $\mathrm{mil}$ & 0.6 & 1 & 0.6 & 0.6 \\
\hline $\mathrm{m} 20$ & 0.8 & 0.6 & 0.6 & 0.6 \\
\hline $\mathrm{m} 21$ & 1 & 0.6 & 0.6 & 0.6 \\
\hline $\mathrm{m} 30$ & 0.6 & 0.6 & 0.6 & 0.8 \\
\hline $\mathrm{m} 31$ & 0.6 & 0.6 & 0.6 & 1 \\
\hline $\mathrm{m} 40$ & 1 & 1 & 0.6 & 0.6 \\
\hline $\mathrm{m} 41$ & 1 & 1 & 1 & 0.6 \\
\hline $\mathrm{m} 42$ & 1 & 1 & 1 & 0.8 \\
\hline $\mathrm{m} 50$ & 1 & 1.2 & 1 & 0.6 \\
\hline
\end{tabular}

bc - column width; hc - column depth; bb - beam width, hb - beam depth.

Unit numbers in meters.

Varying any of the design variables affects multiple sectional stiffness properties of the member at the same time; for example, axial (EA), flexural (EI) and shear (GA) rigidities, 
where $\mathrm{A}$ is the sectional area, I is the momentof-inertia, E is the modulus of elasticity and G is the shear modulus.

Also, it should be noted that the larger column depth not only increases the column stiffness, but also the beam stiffness by reducing the clear distance between the columns (i.e., beam clear span length). Similarly, the larger beam depth affects the column stiffness as well as the beam stiffness. Given this, the direct effects of column flexural rigidity may be assessed only by comparing pairs of models with the same axial and shear rigidities in an approximate way but two different flexural rigidities for the columns. Also, the direct effects of beam flexural rigidity may be roughly evaluated in a similar way. All other design values, including the centerto center distance between the columns, are kept constant among all models. Although the spacing between the exterior columns of a tube structure, along with the member dimensions and the plan aspect ratio, is one of the most influential factors in the tube action, the column spacing is typically selected by architectural requirements; thus, it is excluded from the current investigation. The spacing between exterior columns is $3.6 \mathrm{~m}$.

\section{MODELING AND ANALYSIS ASSUMPTIONS}

ETABS building analysis and design software has been used for the modeling and analysis of this study. Figure 3 illustrates the 3-dimensional ETABS model. Several important modeling and analysis approaches used for the parametric study are summarized in the following:

- Joints between the beams and columns (parts of both the beams and columns belonging to their common regions) are assumed as rigid. Note that varying the column (or beam) depth of the frames changes the beam (or column) length between the column faces, so as to also affect the beam (or column) stiffness due to this assumption.

- The contribution of the slab to the beam stiffness (i.e., T-beam action) is ignored.

- The concrete floors are modeled with rigid diaphragm constraints for lateral force analysis.

- P-delta effects are taken into account by an approximation method imbedded in ETABS (CSI, 2011).

- The flexural stiffness of uncracked shear walls is assumed to correspond to $100 \%$ of the gross section properties, while the flexural stiffness of all spandrel beams and coupling beams is taken as $50 \%$ based on ACI $318-08$, Section
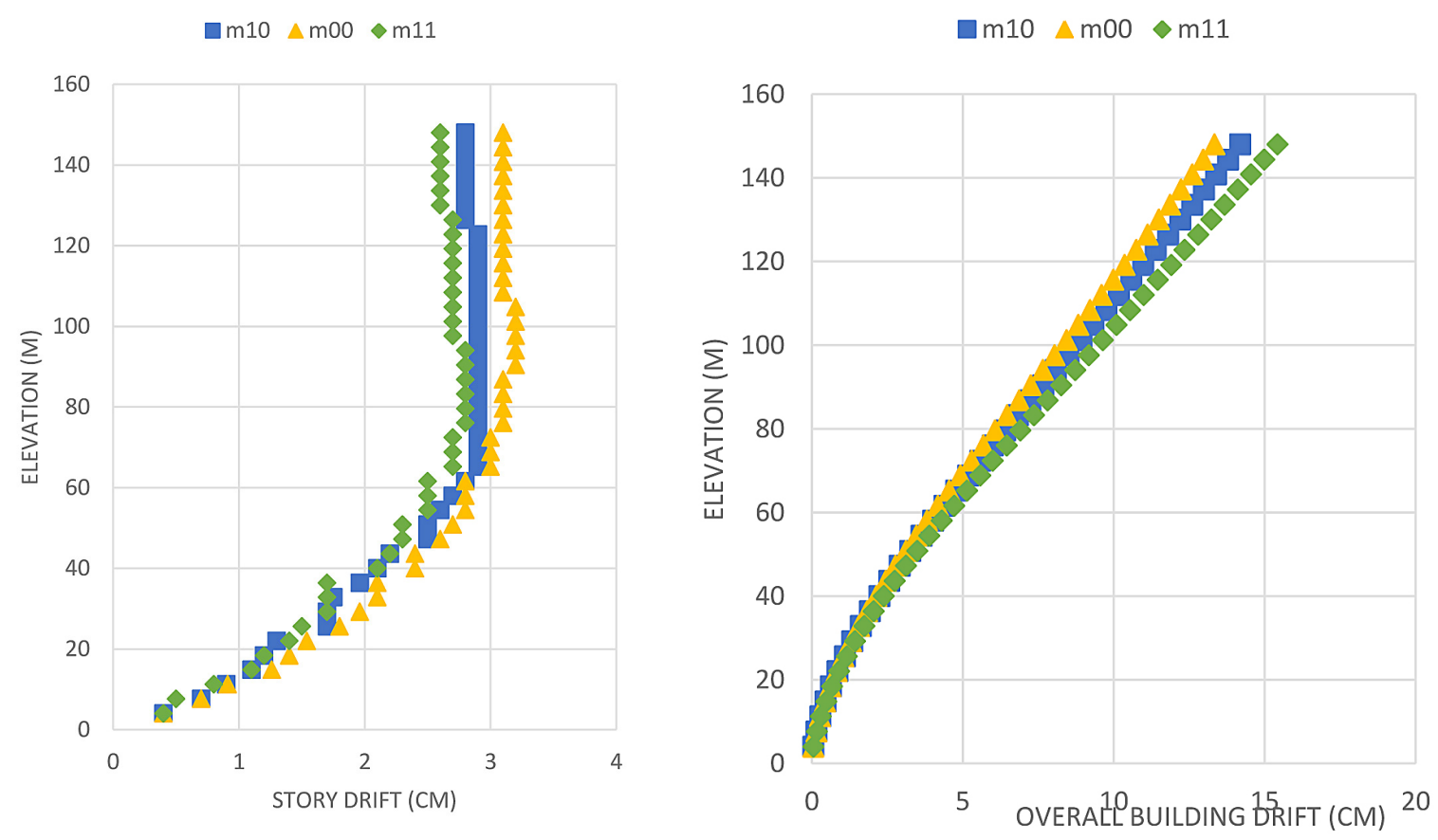

Fig. 2. Story drifts (a) and overall building drift (b) along the building height for three companion models with different column depths under seismic forces at the service-level 

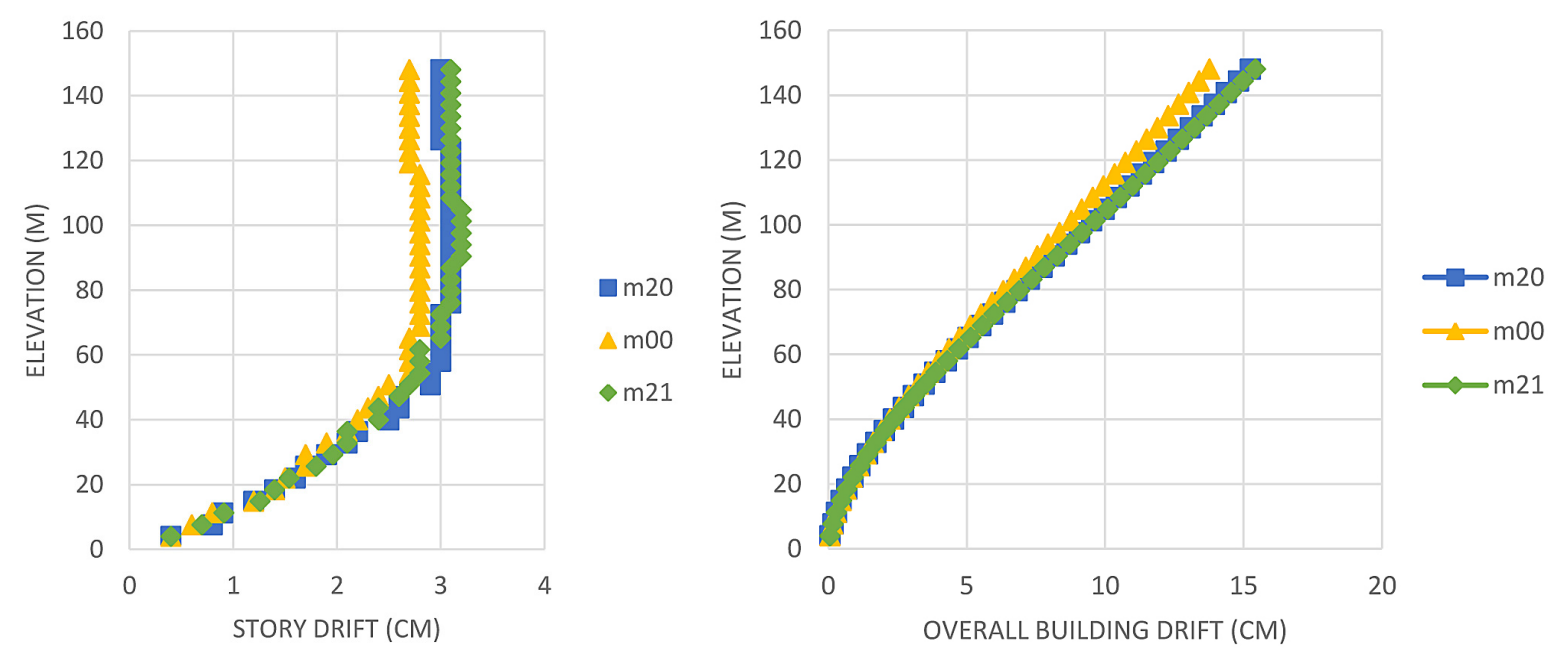

Fig. 3. Effects of the column width on the maximum (critical) story drift (a) and overall building drift (b)

8.8 (ACI 318, 2008). It has been verified by the models that the shear walls are expected not to undertake cracking at all stories under the lateral forces used for this study. Detailed discussions for the finite element modeling of cracked shear walls can be found elsewhere.

\section{STORY DRIFTS}

\section{Effects of column depth and column width}

Figure 2 shows story drifts (a) and overall building drift (b) along the building height for three companion models with different column depths under the service-level seismic forces. For lateral force resistance, the structure mainly uses the exterior column, combination of the moment frames, and the interior shear walls. The level of the story showing the maximum drift lowered when the column depth became larger in both directions, as more tube action affected the overall behavior (see Figure 2). Figure 3 depicts effects of the column width on the maximum (critical) story drift (a) and overall building drift (b), similar column depth increases column width lade to decrease overall building drift and story drift with the difference in which effects of column depth are greater than column width, between studied models increase column depth dimension decreased overall building drift until 13.5 percent while this reduction for increase column width was about 10.6 percent.

\section{Effects of beam depth and beam width}

Figure 4 depicts effects of beam depths on the (a) maximum (critical) story drift and the (b) overall building drift. The effects of the beam depth
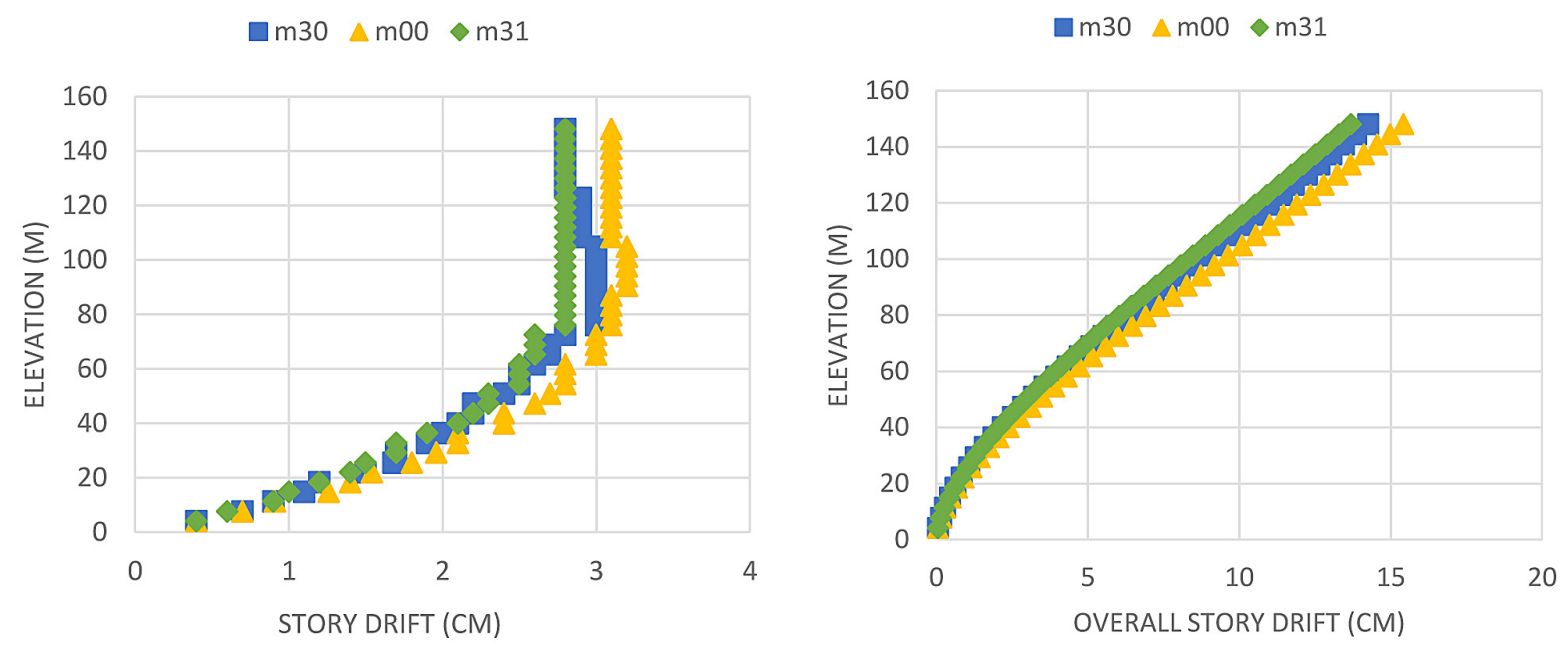

Fig. 4. Effects of beam depths on the (a) maximum (critical) story drift and the (b) overall building drift 

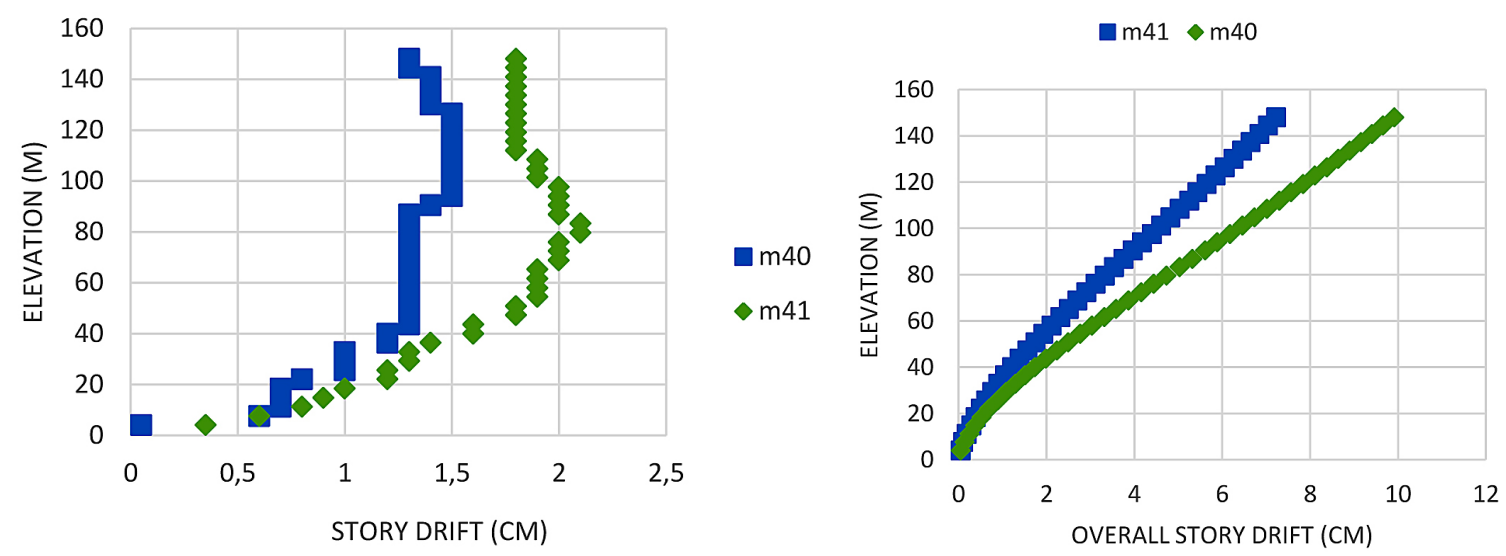

Fig. 5. Effects of beam width on the (a) maximum (critical) story drift and the (b) overall building drift

(hb) on the drifts were similar to effects of column width. However, the effects of the column depth (hc) were quite greater than effects of beam depth. For lateral force resistance, the structure mainly uses the exterior column and interior shear walls played secondary role to resistance lateral forces but one has to consider interior wall role on performance of structure should not be underestimated. Lateral drifts can be most effectively reduced by increasing the column depth. This is likely attributable to the increased flexural rigidity of the building plan (i.e., the tube section), as well as the reduced beam clear span that increases the beam stiffness against relative transverse displacements between the beam ends caused by shear lag. The results presented in this subsection provide quantitative assessment for the impact of change in any sectional dimension of the frame members on the lateral displacement. For two models with different beam width that was compared together ( $\mathrm{m} 40$ and $\mathrm{m} 41$ models) it an increase was seen in beam width reduction overall story drift about 27 percent (Fig. 5b) that is considerable, increase beam width decreases inter story drift too (Fig. 5a).
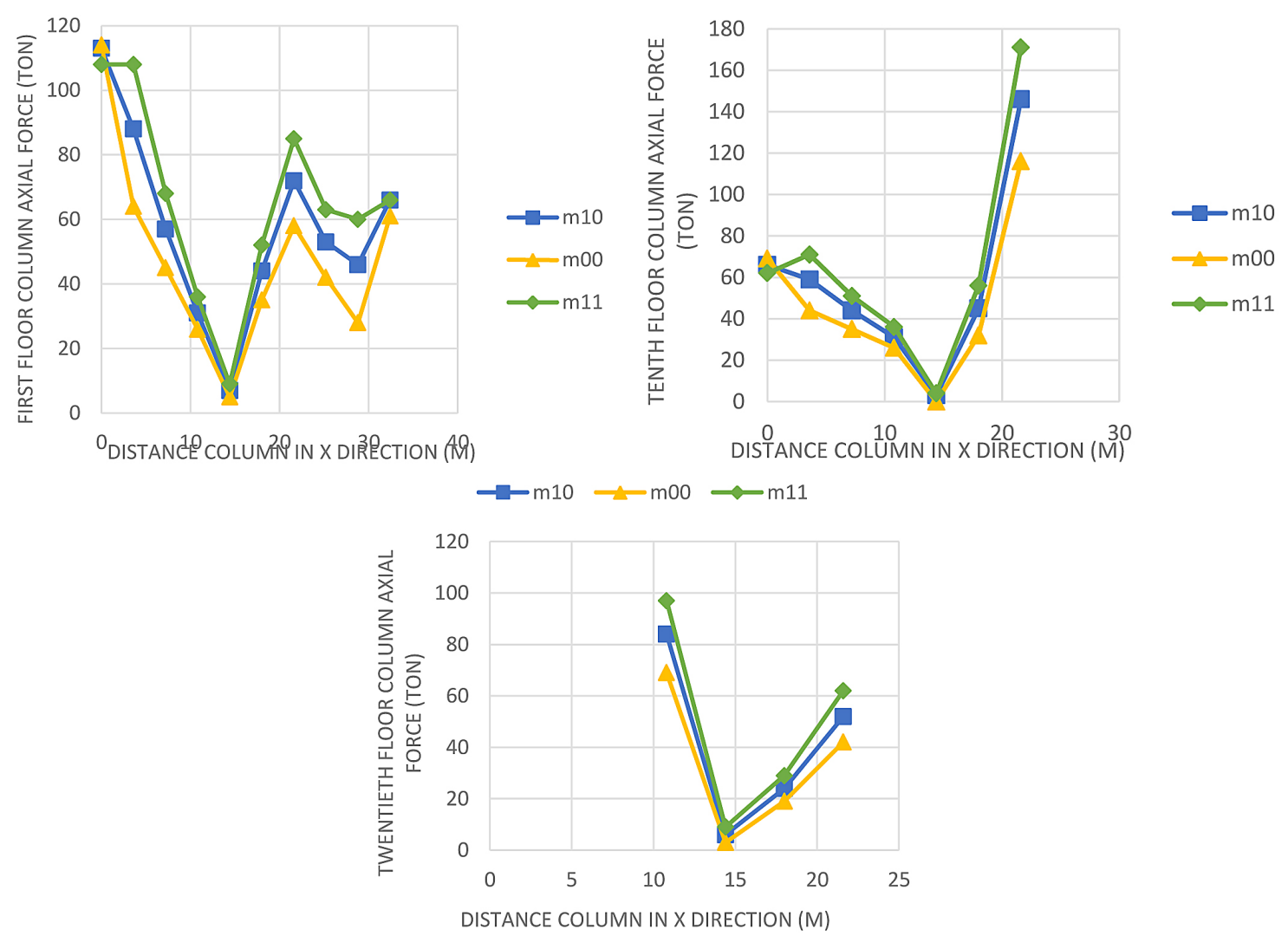

Fig. 6. Column axial force of first, tenth and twentieth floors for web of structure 


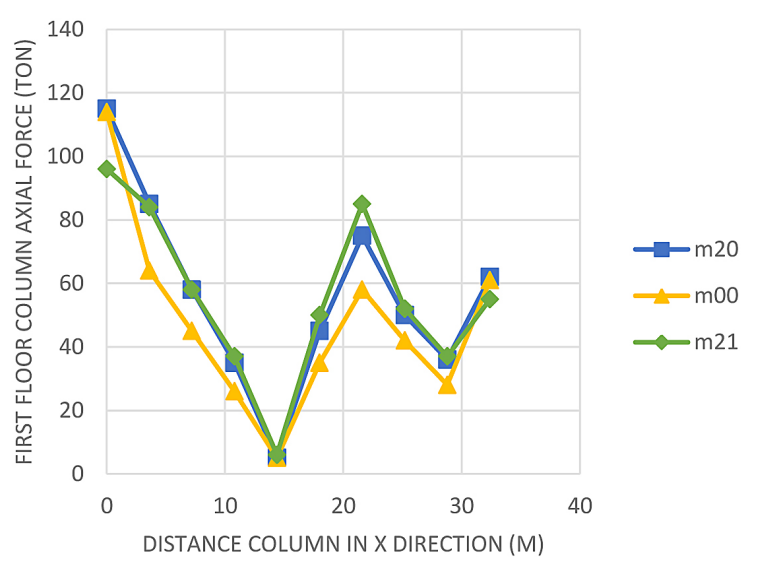

Fig. 7. Comparing column axial force of first floor for three models with varying column width and constant other parameter

\section{DISTRIBUTION OF COLUMN AXIAL FORCES AND STRESSES}

Figure 6 illustrates column axial force of first, tenth and twentieth floors for web of structure. For the web seismic load exerted in $\mathrm{X}$ direction, Figure 6 compares column axial force for three models with different column depth and other constant parameter. Comparing three models with different column depths shows middle columns take gradually increasing forces when the column depth increases and the corner columns axial force decreases. On the other hand, forces of the corner columns decrease only by slight amounts and middle columns axial force growth.
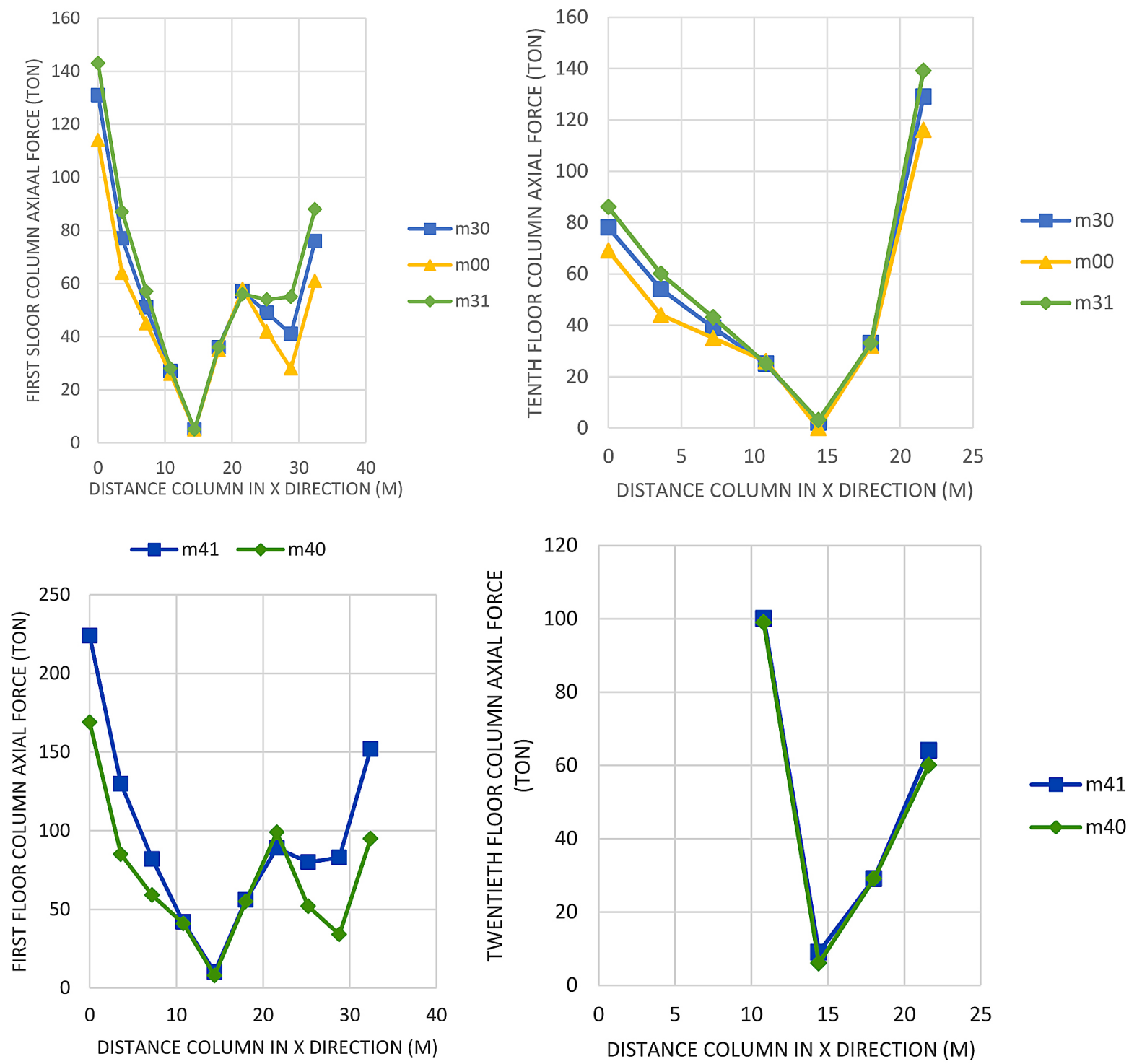

Fig. 8. Comparing column axial force of first, tenth and twentieth floors for three models with varying beam depth, beam width and constant other parameter 
Figure 7 shows comparison of column axial force of first floor for three models with varying column width and constant other parameter, as you can see in Figure 7 increase column width reduction beam clear span and increase middle column axial force so that amply shear lag phenomena. Enhancement beam dimension, depth or width lade to increase corner and middle column axial force and getting away distribution of column axial force from ideal state, in ideal state columns axial force distribution are near to linear condition, with enhancement beam dimension shape of column axial force distribution become closer to the vertical state and getting away from horizontal shape (Fig. 8).

\section{CONCLUSIONS}

Based on the study, the following conclusions can be drawn:

1. Overall building drifts or story drifts of a structure similar to the case study building can be reduced by increasing the stiffness properties of flange and web frame members, on other hand increase column depth had reduction effects on overall building and story drift.

2. Increase beam depth graduate reduction overall building drifts. Effect of beam depth on critical story drift is more than overall building drifts. On other hand increase beam depth reduction critical building more than overall building drifts.

3. Increase column width and beam width reduction overall building drift.

4. Increase column depth, decreases corner columns axial force and increases middle columns axial force and subsequently distribution of axial forces become away from the ideal state. Note that increase in columns depth too much decreases clear beam bay and subsequently stiffness of beam increase to high degree.

5. Increase in depth- laden beam to increase corner columns axial force and increase middle columns axial force. In this case study in- crease beam depth made column axial force away from ideal state.

\section{REFERENCES}

1. ACI 318. Building Code Requirements for Structural Concrete (ACI 318-08) and Commentary (318R-08). American Concrete Institute: Farmington Hills, MI, 2008.

2. Kwan M. Shear lag in shear/core walls. ASCE Journal of Structural Engineering, 122 (9), 1996, 1097-1104.

3. Kristek V, Bauer K. Stress distribution in front columns of high rise buildings. ASCE Journal of Structural Engineering, 115 (5), 1993, 1326-1337.

4. Lee K-K, Lee L-H, Lee E-J. Prediction of shearlag effects in framed-tube structures with internal tube(s). The Structural Design of Tall Buildings, 11, 2002, 73-92.

5. Singh Y, Nagpal K. Negative shear lag in framedtube buildings. ASCE Journal of Structural Engineering, 120 (11), 1994, 3105-3121.

6. Coull A, Abu El Magd S. A. Analysis of wideflanged shearwall structures. Reinforced concrete structures subjected to wind and earthquake forces: ACI special publication 63, Paper No. SP63-23, Concrete Institute, Detroit, MI, 1980, 575-607.

7. Coull A, Ahmed A. A. Deflections of framedtube structures. Journal of Structural Engineering, ASCE, 104 (5), 1978, 857-862.

8. ETABS. Three dimensional analysis of building system. Computers and Structures, Berkeley, USA, 1989.

9. Foutch D. A, Chang P. C. 1982. A shear lag anomaly. Journal of Structural Engineering, ASCE 108 (ST7), 1653-1657.

10. Kwan A. K. H. Simple method for approximate analysis of framed tube structures. Journal of Structural Engineering, ASCE 120 (4), 1994, 1221-1239.

11. Kwan A. K. H. Shear lag in shear/core walls. Journal of Structural Engineering, ASCE 122 (9), 1996, 1097-1104.

12. Lee K. K. Orthotropic box beam analogy for analysis of framed tube structures with multiple internal tubes. PhD Thesis, Griffith University, Nathan, Queensland, 1999. 